\title{
COVID-19 Induced Economic Slowdown and Mental Health Issues
}

\begin{abstract}
Yimiao Gong1,2t, Xiaoxing Liu't, Yongbo Zheng 1,2, Huan Mei3,4, Jianyu Que', Kai Yuan', Wei Yan ${ }^{1}$, Le Shi ${ }^{1}$, Shiqiu Meng ${ }^{3 *}$, Yanping Bao ${ }^{3,4 *}$ and Lin Lu ${ }^{1,2 *}$

${ }^{1}$ Peking University Sixth Hospital, Peking University Institute of Mental Health, NHC Key Laboratory of Mental Health (Peking University), National Clinical Research Center for Mental Disorders (Peking University Sixth Hospital), Beijing, China,

${ }^{2}$ Peking-Tsinghua Centre for Life Sciences and PKU-IDG/McGovern Institute for Brain Research, Peking University, Beijing,

China, ${ }^{3}$ National Institute on Drug Dependence and Beijing Key Laboratory of Drug Dependence, Peking University, Beijing,

China, ${ }^{4}$ School of Public Health, Peking University, Beijing, China
\end{abstract}

OPEN ACCESS

Edited by:

Chi Keung Lau,

Teesside University, United Kingdom

Reviewed by:

Luigi Isaia Lecca,

University of Cagliari, Italy

Mohammad Farris Iman Leong

Bin Abdullah,

Universiti Sains Malaysia, Malaysia Ren Zhang

Texas State University, United States

*Correspondence:

Shiqiu Meng

mengshiqiu@bjmu.edu.cn

Yanping Bao

baoyp@bjmu.edu.cn

Lin Lu

linlu@bjmu.edu.cn

${ }^{t}$ These authors have contributed equally to this work

Specialty section:

This article was submitted to

Environmental Psychology,

a section of the journal

Frontiers in Psychology

Received: 15 September 2021

Accepted: 09 February 2022

Published: 04 March 2022

Citation:

Gong Y, Liu X, Zheng Y, Mei H,

Que J, Yuan K, Yan W, Shi L, Meng S,

Bao Y and Lu L (2022) COVID-19

Induced Economic Slowdown

and Mental Health Issues.

Front. Psychol. 13:777350

doi: 10.3389/fpsyg.2022.777350
The COVID-19 pandemic has pressed a pause button on global economic development, and induced significant mental health problems. In order to demonstrate the progressed relationship between the pandemic, economic slowdown, and mental health burden, we overviewed the global-level gross domestic product changes and mental problems variation since the outbreak of COVID-19, and reviewed comprehensively the specific sectors influenced by the pandemic, including international trade, worldwide travel, education system, healthcare system, and individual employment. We hope to provide timely evidence to help with the promotion of policymakers' effective strategies in mitigating economic losses induced by the pandemic; we suggest different governments or policy makers in different countries to share information and experience in dealing with COVID-19-induced economic slowdown and promote COVID-19 vaccine popularization plan to protect every individual worldwide against the coronavirus essentially; and we appeal international information share and collaboration to minimize stigmatization related to adverse mental consequences of COVID-19 and to increase mental health wellbeings of people all over the world.

Keywords: COVID-19, economic slowdown, mental health issues, GDP, international trade, unemployment, healthcare system, education system

\section{INTRODUCTION}

Since the first outbreak of COVID-19 caused by Severe Acute Respiratory Syndrome Coronavirus 2 at the end of 2019, the coronavirus has been keeping hovering all over the world and depressing the world populations' lives like a huge mist. With tens of thousands of individuals infected worldwide, medical emergency systems activated, and individuals' normal lives damaged, COVID19 has pressed a pause button on economic development and induced significant mental health problems (Cross et al., 2020; Guan et al., 2020; Keogh-Brown et al., 2020; Sarkodie and Owusu, 2020). Right following outbreak, some researchers started paying attention to the impact of the pandemic on economic loss, and many others focused on investigating the influence on mental health burden. However, it is important to learn about the interrelation of the three on the process of establishing and implementing cost-effect strategies to fight against the pandemic and the plight related to COVID-19. Thus, in this review article, we aimed to present the connection between the 
three - we overviewed the changes of global-level gross domestic product (GDP) and variation in mental problems since the outbreak of COVID-19, reviewed comprehensively the specific sectors influenced by the pandemic, and looked at the role that cultural and national differences might play in this relationship.

\section{OVERVIEW OF THE EFFECT OF COVID-19 ON ECONOMIC AND MENTAL HEALTH}

Economic activities are easily affected by various social factors, such as monetary policies (Balke et al., 2017; Zhang, 2019; An et al., 2021), credit shocks (Balke et al., 2021), and major public events like COVID-19 pandemic (Shang et al., 2021; Zhao Y. H. et al., 2021). The global economy encountered a serious recession in the second quarter of 2020. To demonstrate the economic changes more clearly, we summarized recent 5year GDP changes in 16 countries worldwide and recent 3-year changes in GDP growth rates in major economies according to The World Bank (2021), International Monetary Fund (IMF) (2021), and Japanese Cabinet Office (National Accounts of Japan, 2021) (Figures 1A-D).

For most demonstrated countries, GDP increased between 2016 and 2019, whereas the increasing trend stopped abruptly in 2019 (Figures 1A,B). Negative GDP growth rates were encountered by most countries in 2020, except for China, based on World Bank and IMF estimations (Figures 1C,D). Although a causal relationship or direct association between economic shrink and COVID-19 cannot be concluded through the data, the pandemic played at least some roles in the economic crisis since 2019 and 2020 were the years when COVID-19 outbroke. In terms of a World Bank estimation, COVID-19 pandemic pushed between 88 million and 115 million people into extreme poverty in 2020. A research team from Italy used electricity market data to monitor real-time economic impact of the containment policies. According to their estimation, the 3 weeks of the most repressive outbreak period in Italy reduced the corresponding national GDP by about 30\% (Fezzi and Fanghella, 2020). Another research suggested that the estimated GDP loss caused by COVID-19 related unemployment had reached 7.6 trillion, and the overall estimated GDP decline resulted from the pandemic was 3.4\% (Arredondo et al., 2021). China, as the only country with no negative GDP growth, also encountered a huge challenge in the economic development due to COVID-19. For example, Zhao J. et al. (2021) estimated the economic burden of movement restriction policies (MRPs) and found that the first wave of COVID-19 in China resulted in a cost of 278 billion USD. Another Chinese team investigated different aspects of economic costs more carefully and concluded that although healthcare costs including inpatient care costs and other medicines costs account for a major part of economic burden in China, productivity losses which were mostly attributable to the effect of MRPs on people who did not have COVID-19 accounted for 99.8\% of societal costs. Moreover, the control measures used to prevent COVID-19 spread have resulted in huge productivity losses which amounted to $2.7 \%$ (US\$ 382.29 billion/US\$ 14.14 trillion) of China's annual GDP (Jin et al., 2021).

Mental health changes related to COVID-19 outbreak have been investigated widely. Depression, anxiety, insomnia, acute stress or post-traumatic stress disorder (PTSD), suicide behaviors are common mental health problems which individuals suffer during COVID-19 (Bao et al., 2020; Meng et al., 2020; Shi et al., 2020; Wang et al., 2020; Xu et al., 2021). Table 1 gives a summary of findings that explored variation of prevalence of mental health problems relative to the COVID-19 outbreak period. According to most studies, prevalence of mental problems was the highest during the outbreak period compared with both before outbreak and post outbreak (Barrea et al., 2020; Gallagher and Wetherell, 2020; Li X. Y. et al., 2020; McGinty et al., 2020; Salfi et al., 2020; van der Velden et al., 2020; Capuano et al., 2021; Creese et al., 2021; Jalal et al., 2021; Johnson et al., 2021; Martinezde-Quel et al., 2021; Megalakaki et al., 2021; Mei et al., 2021; Pieh et al., 2021; Ramiz et al., 2021; Yang et al., 2021). One study from Argentine reported an even higher prevalence of sleep problems and moderate to severe depressive symptoms post outbreak (32.1 and 47.8\%, respectively) compared with that during outbreak (23.1 and $24.3 \%$, respectively). Shi et al. (2021a) from China reported a higher persistent prevalence of depression and insomnia (33.6 and $35.3 \%$ vs. 30 and $29.8 \%$, respectively) from first wave of pandemic to the aftermath of the outbreak (Shi et al., 2021a). These reports suggested the huge adverse effect of COVID-19 outbreak on mental health conditions (Badellino et al., 2021).

The economic crisis triggered by COVID-19 pandemic can be considered as one possibility accounting for COVID-19related mental health problems (McInerney et al., 2013). It is generally recognized that economic crisis has a vicious impact on mental health (Sun et al., 2020). One-month prevalence of major depression was found to be $8.2 \%$ in the Greek population in 2011, the year that the country was in the throes of economic collapse, which was 2.6 times compared to the prevalence rate in 2008 (Economou et al., 2013). Since 2007, nearly all European countries have encountered the economic shock and the situation was the worst in Spain. Compared with the pre-crisis period of 2006, the proportion of patients with mood, anxiety, somatoform, and alcohol-related disorders had a substantial and significant increase during the economic crisis period. Families experiencing unemployment and mortgage payment difficulties suffered the most (Gili et al., 2013). The October 2008 stock market crash in the United States had put a large number of older adults into depressive status and the adverse effect of sudden economic shock was the largest among individuals with high levels of stock holding prior to the crash. In the case of COVID-19, a sharp decline or negative growth of GDP is a macroeconomic reflection of the pandemic's impact on per capita income (Capello and Caragliu, 2021). Individuals encountered job loss and/or income contraction due to the pandemic, which would contribute to their worse life quality and subjective wellbeing (Rasul et al., 2021). Therefore, in this review, we propose a progressive relationship between COVID19, economic slowdown, and mental health problems (Figure 2). That is, we believe that the economic slowdown induced by 


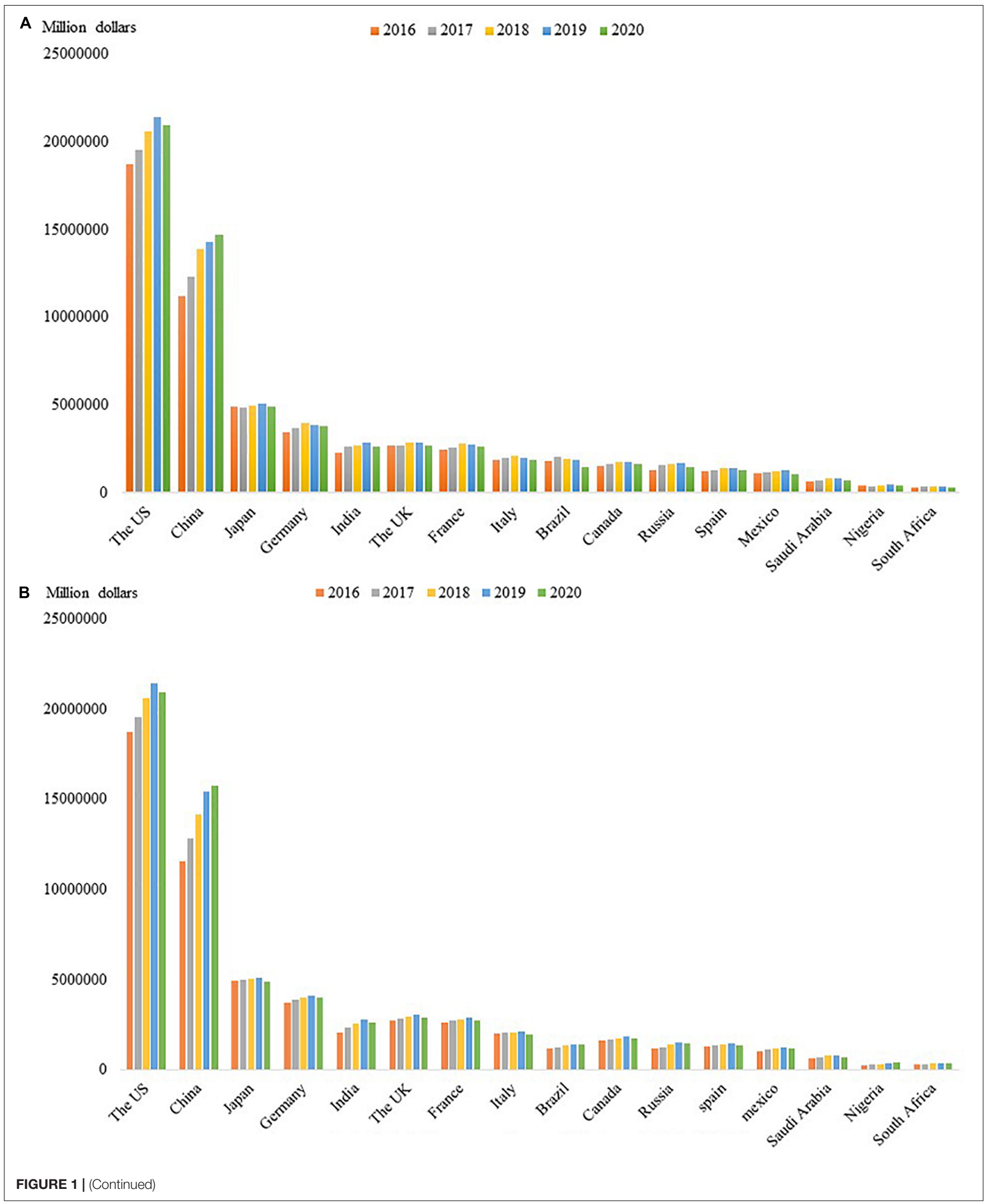



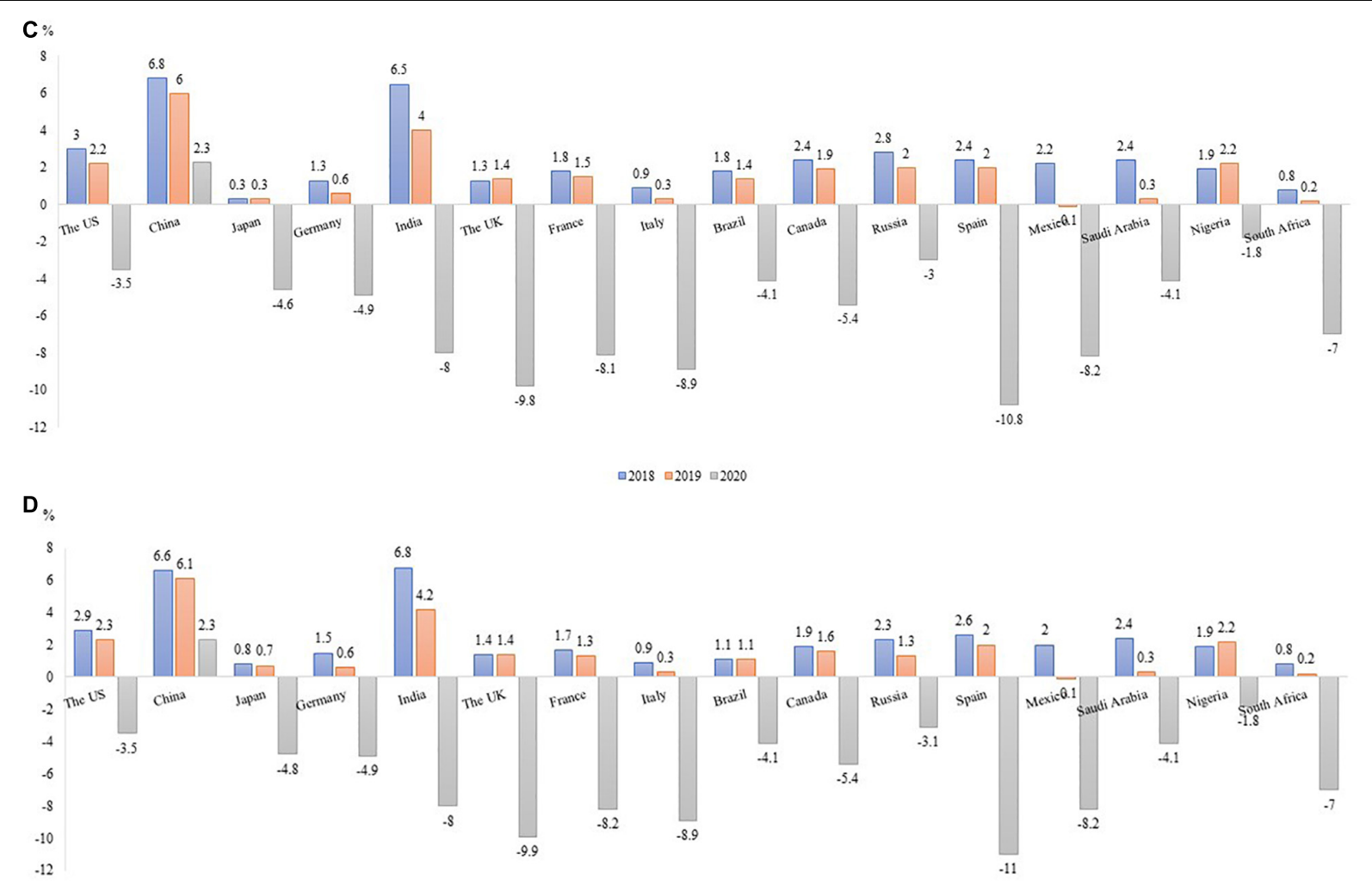

$\square 2018 \square 2019 \square 2020$

FIGURE 1 | (A) GDP Changes from 2016 to 2020 (World Bank). Based on data from the World Bank database, the change in GDP of the world's major economies from 2016 to 2020 is calculated in current US dollars (August 21, 2021). The World Bank database lacks the GDP data of Japan in 2020 . The data here comes from the Statistics of the Japanese Cabinet Office and is converted to current US dollars (Japanese Cabinet Office: https://www.esri.cao.go.jp/jp/sna/menu.html). (B) GDP Changes from 2016 to 2020 (IMF). Based on data from International Monetary Fund (IMF) database, the change in GDP of the world's major economies from 2016 to 2020 is calculated in current US dollars (September 8, 2021). The IMF database lacks 2020 GDP data for China, India, Russia and Nigeria, which are derived from the World Bank database and converted to current US dollars. (C) Changes in annual GDP growth (\%) rates in major economies (World Bank). Based on data from the World Bank database. The World Bank database lacks the GDP data of Japan in 2020. The data here comes from the Statistics of the Japanese Cabinet Office (Japanese Cabinet Office: https://www.esri.cao.go.jp/jp/sna/menu.html). (D) Changes in annual GDP growth (\%) rates in major economies (IMF).

COVID-19 pandemic is interrelated with many negative mental health consequences during this period. In the next part of this review, we will look into more details about the interrelationship between the three.

\section{SPECIFIC SECTORS IMPACTED BY COVID-19 AND RELATED MENTAL PROBLEMS}

In the following session, we list specific economic impacts of COVID-19 pandemic, including international trade, travel, education system, healthcare system, and individual employment, as well as mental health problems related to these economic impacts.

\section{International Trade Decline and Associated Mental Health Problems}

COVID-19 created an international trade decline through reducing both demand and supply. For example, China is one of the biggest countries worldwide exporting manufactured goods, whereas, export prohibitions and restrictions introduced by over 80 countries and customs territory due to the pandemic blocked the just-in-time manufacturing between China and the other areas in the world and drove a huge chock on manufacturing market (Barlow et al., 2021). Estimated contraction of total global merchandise trade was by $9.2 \%$ in 2020 , with a hard hit on supplies of pharmaceuticals and medical equipment, leading to detrimental consequences for physical and mental health (Barlow et al., 2021). Many global trades nowadays focus not on price the most but on relation the most. In the relationdriven agent-based global trade model, the role of relational factors including trust, familiarity, reputation, trade history and conflicts in countries' trade behavior is very important. Healthy global trade relationship with close international interaction and communication has been suggested to improve the food and nutrition security of countries in Africa, Asia and Latin America and successively promote a healthier and more balanced diet (Ge et al., 2021). COVID-19 has a negative effect on the balance of the relation-driven global trade and the limited 
TABLE 1 | Summary of findings investigating prevalence of mental health problems relative to the COVID-19 outbreak period.

\begin{tabular}{|c|c|c|c|c|c|c|}
\hline References & Site & Participants & Outcomes & Prevalence-Before & Prevalence-During & Prevalence-Post \\
\hline $\begin{array}{l}\text { Badellino et al. } \\
\text { (2021) }\end{array}$ & Argentine & general population & bad sleep quality & / & $23.1 \%(459 / 1985)$ & $32.1 \%(912 / 2839)$ \\
\hline \multirow[t]{2}{*}{ Barrea et al. (2020) } & Italy & general population & poor sleep quality & $50.4 \%(61 / 121)$ & / & $81 \%(98 / 121)$ \\
\hline & & & $\begin{array}{l}\text { moderate to severe } \\
\text { depression }\end{array}$ & / & $24.3 \%(482 / 1985)$ & $47.8 \%(1357 / 2839)$ \\
\hline \multirow[t]{2}{*}{$\begin{array}{l}\text { Capuano et al. } \\
\text { (2021) }\end{array}$} & Italy & $\begin{array}{c}\text { patients with } \\
\text { physical disorder }\end{array}$ & depression & $11.90 \%(8 / 67)$ & $11.90 \%(8 / 67)$ & / \\
\hline & & & anxiety & $11.90 \%(8 / 67)$ & $16.40 \%(11 / 67)$ & / \\
\hline \multirow[t]{4}{*}{ Creese et al. (2021) } & United Kingdom & $\begin{array}{l}\text { older adults (age M } \\
50 \text { ) }\end{array}$ & mild depression & $13.2 \%(392 / 3281)$ & 19\% (634/3281) & / \\
\hline & & & $\begin{array}{l}\text { moderate-to-severe } \\
\text { depression }\end{array}$ & $4.1 \%(124 / 3281)$ & $5.6 \%(185 / 3281)$ & / \\
\hline & & & mild anxiety & $9.3 \%(276 / 3281)$ & $12.6 \%(415 / 3281)$ & / \\
\hline & & & $\begin{array}{l}\text { moderate-to-severe } \\
\text { anxiety }\end{array}$ & $2.2 \%(66 / 3281)$ & $2.7 \%(89 / 3281)$ & / \\
\hline \multirow{2}{*}{$\begin{array}{l}\text { Gallagher and } \\
\text { Wetherell (2020) }\end{array}$} & United Kingdom & caregivers & depression & $16.7 \%(225 / 1349)$ & $21.6 \%(291 / 1349)$ & / \\
\hline & & non-caregivers & depression & $12.1 \%(748 / 6178)$ & $17.9 \%(1106 / 6178)$ & / \\
\hline Jalal et al. (2021) & Saudi Arabia & $\begin{array}{c}\text { students studying } \\
\text { bachelor's degree } \\
\text { programs }\end{array}$ & bad sleep quality & $70.1 \%(440 / 628)$ & 79.9\% (502/628) & / \\
\hline \multirow{2}{*}{$\begin{array}{l}\text { Johnson et al. } \\
\text { (2021) }\end{array}$} & Norway & general population & depression & / & 23\% (659/2868) & $16.8 \%(250 / 1489)$ \\
\hline & & & anxiety & / & 23.3\% (667/2868) & $13.8 \%(205 / 1489)$ \\
\hline \multirow[t]{2}{*}{ LiX. Y. et al. (2020) } & Wuhan, China & $\begin{array}{l}\text { anesthesiologists } \\
\text { and operating room } \\
\text { medical staffs }\end{array}$ & depression & / & $41.6 \%(82 / 197)$ & $13.2 \%(26 / 197)$ \\
\hline & & & anxiety & / & $43.1 \%(85 / 197)$ & $15.7 \%(31 / 197)$ \\
\hline $\begin{array}{l}\text { Martinez-de-Quel } \\
\text { et al. (2021) }\end{array}$ & Spain & general population & poor sleep quality & $63.40 \%(102 / 161)$ & $75.2 \%(121 / 161)$ & \\
\hline McGinty et al. (2020) & United States & general population & stress & $3.9 \%(991 / 25417)$ & $13.6 \%(199 / 1468)$ & / \\
\hline \multirow[t]{4}{*}{ Mei et al. (2021) } & China & pregnant & mild depression & $20.5 \%(482 / 2352)$ & $36.2 \%(192 / 531)$ & / \\
\hline & & & $\begin{array}{l}\text { moderate } \\
\text { depression }\end{array}$ & $0.6 \%(13 / 2352)$ & $10.4 \%(55 / 531)$ & / \\
\hline & & & mild anxiety & $24.7 \%(580 / 2352)$ & $26.9 \%(143 / 531)$ & / \\
\hline & & & moderate anxiety & $3.1 \%(73 / 2352)$ & $4.5 \%(24 / 531)$ & / \\
\hline $\begin{array}{l}\text { Megalakaki et al. } \\
(2021)\end{array}$ & France & general population & $\begin{array}{l}\text { COVID-19 } \\
\text { peritraumatic } \\
\text { distress }\end{array}$ & / & $35.5 \%(398 / 1123)$ & $17.2 \%(40 / 232)$ \\
\hline \multirow[t]{3}{*}{ Pieh et al. (2021) } & Austria & general population & moderate & / & $14.6 \%(64 / 437)$ & $15.6 \%(68 / 437)$ \\
\hline & & & moderate to severe & l & $18.3 \%(80 / 437)$ & $19.7 \%(86 / 437)$ \\
\hline & & & $\begin{array}{c}\text { depression } \\
\text { moderate anxiety }\end{array}$ & / & $16.5 \%(72 / 437)$ & $15.6 \%(68 / 437)$ \\
\hline \multirow[t]{2}{*}{ Ramiz et al. (2021) } & France & general population & depression & $27 \%(278 / 5356)$ & $27.6 \%(341 / 1237)$ & / \\
\hline & & & anxiety & $17.3 \%(180 / 5476)$ & $20.1 \%(248 / 1237)$ & / \\
\hline \multirow[t]{6}{*}{ Salfi et al. (2020) } & Italy & woman & moderate to & I & $13.12 \%(254 / 2701)$ & $11.63 \%$ \\
\hline & & & severe insomnia & & & $(314 / 2701)$ \\
\hline & & man & & l & $9.37 \%(253 / 2701)$ & $12.02 \%$ \\
\hline & & & & & & (324/2701) \\
\hline & & woman & depression & / & $7.20 \%(194 / 2701)$ & $6.50 \%(175 / 2701)$ \\
\hline & & man & & / & $4.47 \%(120 / 2701)$ & $5.71 \%(154 / 2701)$ \\
\hline \multirow[t]{7}{*}{ Shi et al. (2021a) } & China & general population & depression & / & $30 \%(3151 / 10492)$ & $33.6 \%$ \\
\hline & & & & & & (3528/10492) \\
\hline & & & anxiety & / & $35.2 \%(3693 / 10492)$ & $32.5 \%$ \\
\hline & & & & & & $(3415 / 10492)$ \\
\hline & & & insomnia & / & 29.8\% (3127/10492) & $35.3 \%$ \\
\hline & & & & & & (3701/10492) \\
\hline & & & $\begin{array}{l}\text { any mental health } \\
\text { symptoms }\end{array}$ & / & $46.4 \%(4865 / 10492)$ & $45.1 \%(4733 / 10492)$ \\
\hline $\begin{array}{l}\text { van der Velden et al. } \\
(2020)\end{array}$ & Netherlands & general population & $\begin{array}{l}\text { anxiety and } \\
\text { depression }\end{array}$ & $7.2 \%(239 / 3983)$ & $7.8 \%(257 / 2980)$ & / \\
\hline Yang et al. (2021) & Hangzhou & general population & depression & $13.7 \%(431 / 4144)$ & $20.2 \%(636 / 3153)$ & / \\
\hline
\end{tabular}




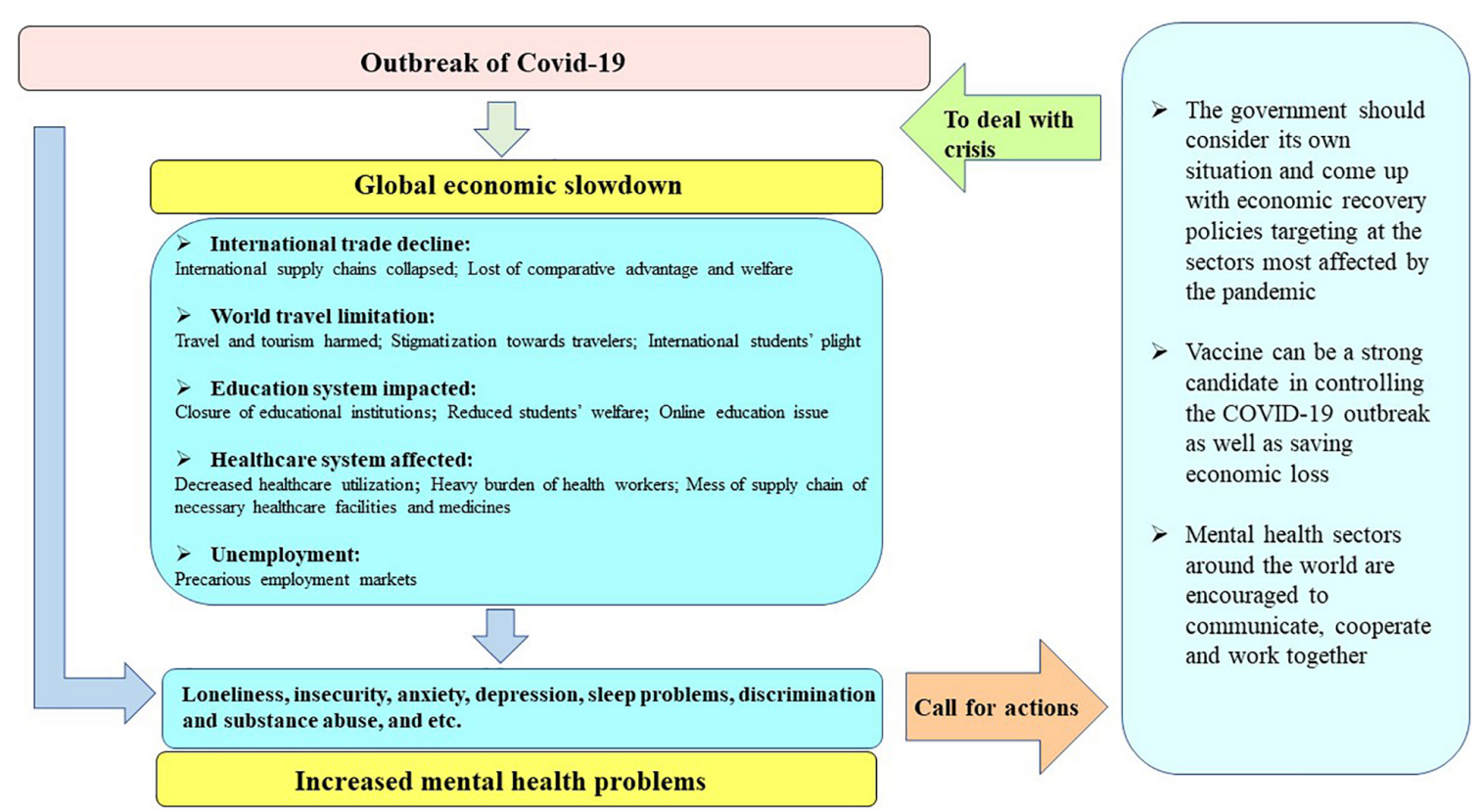

FIGURE 2 | Summary flow chart.

communication among countries will lead to a huge alternation of individual physical and mental wellbeing eventually.

Besides, as for individuals living in border areas and those who rely on international supply chains to earn lives, the collapse of many international supply chains is like a bolt from the blue. The UN World Food Programme estimated that by the end of 2020 , the number of people suffering from severe hunger will almost double due to the pandemic. Theories of international trade propose that foreign trade can lead to a society's ultimate gain in comparative advantage and welfare, which is significant for the social members' mental health (Lin et al., 2020). The team of Lin et al. (2020) applied a fixed effects regression model to explore the prevalence of depressive disorders as a function of international trade and found that a $100 \%$ increase in the value of international trade indicated a $0.09 \%$-point decrease in the prevalence of depressive disorders, and vice versa. Similarly, import competition which disproportionately brought wealth shock on industry labors could have a large negative impact on individual mental health, which can even have negative spillovers to other family members' mental wellbeing (Colantone et al., 2019). Hence, the affected international trade by COVID-19 pandemic is not only an unfortune for global economic growth, but also for individual mental wellbeing.

\section{Worldwide Travel Limitation and Potential Mental Health Problems}

The World Travel and Tourism Council warned that the outbreak of COVID-19 might put 50 million jobs in the global travel and tourism sector into risk, leaving the tourism sector as one of the hardest-hit due to the pandemic (Ataguba, 2020; Nicola et al., 2020; Siddiquei and Khan, 2020; Rasul et al., 2021). In South
Asia, the travel and tourism sector created about 50 million jobs in 2018, which contributed to a significant amount of national GDP. However, the outbreak of COVID-19 and the mitigation measure drove demands in tourism and travel into collapse all of a sudden. Chinese visitors received by Vietnam dropped from about 1.45 million in the first quarter of 2019 by 644,000 in January of 2020, which resulted in a huge economic loss (Nicola et al., 2020). On March 12, 2020, the Nepal government canceled all Everest expeditions slated for the spring season, thus, expenses including US\$4 million annual collections in royalties from Everest climbing permits and US\$40,000-90,000 other expenses were in loss (Rasul et al., 2021). In the trekking sector alone in South Asia, approximately 20,000 tour guides would lose their jobs due to the tourism demand contraction, up to 60,000 employees in the hospitality sector in major capitals were affected, and 40-50 million job cuts were imminent from big hotels, travel agencies and tour operators in India (Rasul et al., 2021). Implement of travel ban compelled the cancelation of a number of airlines, such as Lufthansa and Cathay Pacific, Chinese airlines, Singapore Airlines, etc. Employees in these companies were asked to stay at home and there might be a possibility of layoffs due to the reduced number of flights (Siddiquei and Khan, 2020).

Travel should have been a wholesome activity for most people. On the trip, travelers from different countries and regions can exchange their unique cultures and happiness with each other through active communication and interaction. However, as governments across countries advised their citizens to avoid unnecessary travel, subjective stigmatization toward travelers was developed, especially toward those belonging to Coronavirusprone countries. This feeling could be a culprit for further mental health problems among the population. For individuals who have traveled in the epidemic area before the outbreak, 
according to research, they were more likely to suffer from internalized stigmatization associated with the travel experiences. They may develop internal fear of discrimination and exclusion by other members of the community and further develop negative emotions and cognitions such as self-deprecation, feeling dirty, and self-blame, and in more severe cases, symptoms of anxiety and depression will make the traveler to suffer a lot (Li J. et al., 2020).

A special group of "travelers" is the team of international students who travel to another country with different cultures and local customs and practices, and who will return to their own countries after the learning experience. With the impact of COVID-19, many international students had to return to their home country or region and were unable to go back to school for classes. These students faced a wide range of transitional events and ongoing stressors as they had to adapt to new academic environments and demands in order to keep up with their studies. There are also international students unable to return to their families and friends in the home country due to travel restrictions and extremely high travel expenses. They are away from their central social support systems and worried about their family members' conditions, all of which can be great challenges during the special period and hence affect their mental health (Lai et al., 2020). An investigation showed that $84.7 \%$ of the studied international students reported moderateto-high perceived stress since outbreak of the pandemic, $12.1 \%$ had moderate-to-severe symptoms of anxiety and depression, and $17.1 \%$ had moderate-to-severe symptoms of insomnia (Lai et al., 2020). Feeling lonely is the main concern for international students who undergo a self-isolation process. Economic shock brought by the pandemic put international students' lives in the host country in more difficulty since the price of commodities could be higher than usual. Students who are about to graduate could feel more stressed because of the unforeseen future including unknown graduate dates. Research showed that international students facing job-hunting, severe economic pressure, and poor self-rated health status had higher levels of stress, anxiety, depression, and PTSD symptoms (Song et al., 2021; Wilczewski et al., 2021). Many international Chinese students also experience discrimination and isolation in some countries due to being deemed as potential coronavirus carriers, which can lead to mental problems such as denial, stress, anxiety, and fear (Zhai and Du, 2020). Fortunately, social support was shown to be a protective factor for mental health wellbeing. More social interaction and communication will help keep individuals' positive emotions (Li J. et al., 2020).

\section{Education System by COVID-19 and Associated Mental Health Problems}

All levels of the education system, from preschool to tertiary education, has been affected by the outbreak of pandemic. Over 100 countries have imposed a nationwide closure of educational facilities, although different countries implemented various policies with some countries announcing complete closure like in Germany and Italy and other countries announcing targeted closure like in the United Kingdom. In the case of Australia, the higher education sector expected the revenue loss to be AUS $\$ 3-4.6$ billion in the academic year 2019-2020. Besides, the number of international student enrollments in the United States was expected to reduce by at least a quarter, with a huge loss of income from the higher education sector (Thepphakorn et al., 2021). According to the estimation by United Nations Educational Scientific and Cultural Organization (UNESCO), up to 900 million learners were affected by the closure of educational institutions (Nicola et al., 2020). Many parents have to stay at home from work with their children out of school. The United States federal government put school closures as an important strategy for Pandemic Influenza Mitigation. Although effective in reducing virus transmission, previous literature showed that closing schools in the United States for 4 weeks could cost between $\$ 10$ and $\$ 47$ billion which accounted for $0.1-0.3 \%$ of GDP as well as a reduction of 6 to $19 \%$ in key health care personnel (Lempel et al., 2009). Similarly, in the United Kingdom, researchers have found that closing all schools for 4 weeks would cost between 0.1 and $0.4 \%$ of GDP and about $16 \%$ of the workforce would take absenteeism since they were the main caregiver of dependent children (Sadique et al., 2008). Schools were no longer able to provide free school meals for children which had a significant impact on childcare costs for families with young children, especially for low-income families. This added new household expenditure that could otherwise be economized (Alvi and Gupta, 2020). In addition, online learning has become a new fashion of education ushered by the pandemic. Just like a space of classroom as the necessity for face-to-face education, digital technologies and electronic devices are the new necessities for online education. This new normal of education strategy is always fueled by commercialism and the reigning market ideology, compared to the traditional education system. In fact, not all students were able to afford this internet-based economic activity (Pacheco, 2020; Muthuprasad et al., 2021; Rasul et al., 2021). What's more, school closures as a short-term emergency measure to contain pandemic may lead to students' increased dropout possibility from school in the long-term. Based on UNESCO estimation, about 0.32 billion students in India had been affected by school closures since the outbreak of COVID19 , many of whom will be pushed into the labor market without adequate education background (Alvi and Gupta, 2020).

A remote online learning strategy may cause a series of emotional issues for the learners. Unpreparedness to learn an online course, working with "unknown others," unfamiliarity with information technology are all potential risk factors contributing to individuals anxiety. In the case of COVID19, some specific anxious factors are the sudden absence of a scheduled university environment, an unprecedented shift from school to home environment, disrupted learning and classroom routines, increased academic workload, uncertainty about academic progress (Zhao T. et al., 2021). As students encounter a limited opportunity of communication with peers and teachers, they will suffer from the lack of socialization and the stressed feeling of having fallen academically behind other peers. Without proper intervention, these negative feelings can eventually give rise to comorbidities such as depressive symptoms (Li H. et al., 2020). 
Hasan and Bao (2020) evaluated the psychological effects of COVID-19 "e-learning crack-up" with a sample of 400 higher education students in Bangladesh and concluded that fear of academic year loss was a great predictor for students' psychological distress during the pandemic. Extreme feelings of seclusion, helplessness, panic attacks, and comorbid sleep problems have been often reported by student respondents during school closures due to the pandemic (Li H. et al., 2020; Shih et al., 2021; Tzafilkou et al., 2021). What's worse is that study suggested lower educational attainment due to school closure was associated with lifelong mental health problems including but not limited to depression and schizophrenia (Yoshikawa et al., 2020). The mental health of university students was also being affected by abnormality of daily routine, such as lack of daily leisure and social interaction and loss of academic routines, which included classes and clinical sessions. In addition, students who were presented with history of mental illness and chronic medical illness should also be given additional attention as they are prone to develop mental health complications, such as depression and anxiety. A protective factor of utmost important was greater degree of social support received from friends and family members. In addition to the mental health impact, the sudden alteration in the conduct of education in university also lowered the psychological and social aspects of quality of life among university students (Leong Bin Abdullah et al., 2021; Woon et al., 2021a).

\section{Healthcare System Impacted by COVID-19 and Potential Mental Health Problems}

The COVID-19 wreak havocs on the healthcare system. A stable and functional health system should consist of skilled healthcare personnel, well-maintained facilities and infrastructural frameworks, adequate available personal protective equipment (PPE) and medicines, and more importantly, an effective communication with patients (Okereke et al., 2021). The pandemic made a mess of supply chain of necessary healthcare facilities and medicines. Active pharmaceutical ingredients are imported largely from China, India, and the EU, and China is also the biggest exporter of medical devices to the United States. The outbreak of pandemic and implementation of MRPs put the supply chain into risk and contributed to a huge amount of revenue loss (Nicola et al., 2020). Besides, patients reported reduced contact with healthcare providers due to the fear of disease contraction (Okereke et al., 2021). The limited communication between patients and healthcare providers can bring great damage to the otherwise normal healthcare system. Zhang et al. (2020) used a big data approach to measure individual healthcare expenditure and utilization in mainland China. By tracking healthcare utilization before, during and after the Spring Festival in 2020 and 2019, they concluded that total healthcare expenditure and utilization declined by 37.8 and $40.8 \%$, respectively. Due to the pandemic, finite healthcare resources and government grants for healthcare services are allocated to battle COVID-19 (Edoka et al., 2021), thus, many patients have to delay their necessary healthcare such as surgery, dialysis, cancer treatment, physical rehabilitation, and mental healthcare treatment with disruption in services. An investigation established among older adults across 27 European countries found that the prevalence of reported postponed medical care was up to $26 \%$ (Ksinan Jiskrova et al., 2021). The sharp decrease in healthcare utilization can lead to turmoil within the healthcare system. Besides, the post-pandemic increase in healthcare facilities admission of indigent patients, medical reimbursement decrease, and high operating costs to main healthcare workers are all contributing factors to the tsunami of healthcare system induced by COVID-19 (Arredondo et al., 2021).

Healthcare workers (HCWs) as primary personnel within the healthcare system suffer from unprecedented burdens due to the pandemic. A narrative review conducted by Giorgi et al. (2020) recognized HCWs as one of the most vulnerable worker categories that may have negative COVID-19-related mental health effects. During the outbreak period of COVID-19, many HCWs applied for going to the frontline to save more lives. However, they had to face a lot of challenges including reducing the spread of infection of COVID-19, developing suitable shortterm strategies for patients, and formulating long-term plans to cope with the aftershock of this pandemic. Alshekaili et al. (2020) investigated the healthcare settings in Oman and compared mental health outcomes between frontline HCWs and nonfrontline HCWs during COVID-19. They found that HCWs in the frontline group were 1.5 times more likely to report anxiety, stress, and insomnia. The time pressure, increasing workload, and infection risk are all potential "whirlpools" that can drive HCWs to fall into emotional exhaustion, depression, and anxiety (Liang et al., 2020; Que et al., 2020; Wang H. et al., 2021). Even not during the period of pandemic, experiencing high emotional exhaustion has become a daily routine for many HCWs. In the case of United Kingdom, between 31 and 54.3\% of doctors reported a high level of emotional exhaustion before COVID-19 pandemic, not to mention the extreme turmoil condition after pandemic (Imo, 2017). Sticking to the frontline work position means the vacancy in the family position. It has been reported that impaired mental wellbeing such as higher severity of depression and psychological stress lowered the social aspect of the quality of life among healthcare workers during COVID-19 pandemic which is believed to be the consequence of mental disturbance and further worsen the already lowered social interaction within the HCW population due to their commitment in battling the pandemic and saving lives (Woon et al., 2021b). HCWs worry about the health condition and infectious possibility of their families but are not able to take action to protect their families directly by themselves. The worries, feelings of guilt, loneliness, and poor sleep quality all contribute to the consistent reports of HCWs' stress, anxiety, and depressive symptoms (Shreffler et al., 2020; Di Filippo et al., 2021; Repon et al., 2021). Moreover, compared to the other population, HCW were shown to be at nearly three times the risk of infection (Quigley et al., 2021). Even if they are lucky enough to avoid infection, they witness countless infectious cases every day. Hence, it is very easy for them to catch acute stress symptoms or even post-traumatic stress symptoms (PTSS). Yuan et al. (2021) did a meta-analysis on the prevalence of PTSD after infectious disease pandemics in the 21st century and found that HCWs had the highest prevalence of PTSD 
report (26.9\%) compared to the general population and infected patients. A similar review established by d'Ettorre et al. (2021) focused only on the COVID-19 pandemic induced PTSS and reported a rate of up to $73.4 \%$ in regarding to the occurrence of PTSS in HCWs. Social support, referring to a high level of social interaction and communication, is believed to be a protective factor for HCW's mental health wellbeing (Pollock et al., 2020; d'Ettorre et al., 2021; Peng et al., 2021).

\section{Unemployment Under COVID-19 and Associated Mental Health Problems}

In the wake of COVID-19, workers were trapped in precarious employment with a large number of people losing their jobs (Matilla-Santander et al., 2021; Strauss et al., 2021). Pinilla et al. (2021) estimated the unemployment rate in the Spanish employment market in 2020 and found that there was a cumulative increase of $11.9 \%$ in the rate of unemployment due to the outbreak of COVID-19. Millions of people, especially those in low-income and middle-income countries, have been pushed into extreme poverty (Barlow et al., 2021). As for the hospitality labor market, business closure policies were associated with a $20-30 \%$ reduction of non-salaried workers in the food/drink and leisure/entertainment sectors during March-April of 2020 (Huang et al., 2020). The healthcare sector as the fourthlargest employer in India was reported to face $90 \%$ losses due to decreases in out-patient attendance, elective surgeries and international patients, not to mention the healthcare workers individual losses (Gopalan and Misra, 2020). In Hong Kong, the unemployment rate increased from 3.7 to $4.2 \%$ and the underemployment rate jumped from 1.5 to $2.1 \%$ between January and March (Kaur et al., 2020). An inevitable side effect of losing jobs is the loss of their insurance coverage, which further adds burdens to unemployed families, especially those with patients of chronic disease or preexisting mental health disorders (Arredondo et al., 2021).

Research has established a strong association between mental health and work loss or financial insecurity (Bambra, 2011; Reeves et al., 2016). Sudden layoffs and unemployment due to the pandemic contribute to individuals' depression, alcoholism, substance abuse, and even in some cases suicides (Brenner and Bhugra, 2020; Rasul et al., 2021; Shi et al., 2021b), not to mention many unemployed status is long-lasting. Not just the unemployed, the underemployed individuals have also been found to have significant psychosocial stress, annoyance, depression, unfriendliness, and insecurities (Kaur et al., 2020). In fact, even though the labor market started to recover rapidly after the peak period of outbreak, the unemployment rate remained high, for example, in the United States, the unemployment rate remained at 6.9\% in October 2020 (Yao and Wu, 2021). Bocchino et al. (2021) concluded a new syndrome of the unemployed which is generally devastating for individuals and families. They found a greater symptomatology of the unemployment syndrome in the unemployed compared to the employed as stress, deterioration of the quality of life, low self-esteem, hopelessness, low personal satisfaction, anxiety, hostility, impotence, frustration, sleep pattern disorders, fear, feeling of irritability, and lack of adaptive resources and management of stressors. Besides, the unemployed scored higher in abuse of alcohol, tobacco and other harmful substances, which may further develop into substance abuse without a proper coping strategy (Bocchino et al., 2021). Within all the named symptoms of the unemployed syndrome, losing the meaning of life and individual functioning is the most struggling for many individuals, which is the culprit that can give people the biggest blow (Thill et al., 2020; Levy and CohenLouck, 2021; Rosen and Stenbeck, 2021). As employment and personal/household income are the most direct factors related to individuals' mental health conditions in their daily lives, we summarized existed studies that compared unemployed individuals and employed individuals regarding their mental health problems in Table 2 (Banna et al., 2020; Liu et al., 2020; Patabendige et al., 2020; Ueda et al., 2020; Verma and Mishra, 2020; Hassannia et al., 2021; Munoz-Navarro et al., 2021) and the association between income and mental health problems in Table 3 (Banna et al., 2020; Naser et al., 2020; Que et al., 2020; Shi et al., 2020; Verma and Mishra, 2020; Munoz-Navarro et al., 2021; Zheng et al., 2021a). By comparing symptoms of anxiety and stress between the employed and unemployed, Banna et al. (2020) reported that unemployed individuals were three times more likely than the employed to have anxiety symptoms and two times more likely to have stress (Banna et al., 2020). The likelihood of suffering from depression among the unemployed was shown to be as about twice as that among the employed (Verma and Mishra, 2020).

\section{DISCUSSION}

In this paper, we reviewed the current status of global major economies with the influence of the COVID-19, mental health problems induced by the outbreak, as well as particular sectors seriously damaged by the outbreak and related mental health responses. After comprehensively reviewing existing literatures, we propose a progressive relationship between the pandemic, economic slowdown, and negative mental consequences. In summary, outbreak of COVID-19 induced the imbalance of demand and supply in the world market, and the affected international trade contributed to depressive symptoms of those who rely on international supply chains to earn lives. Similarly, limitation of travel across countries due to the pandemic has put tourism economy into gloomy, and as a consequence, those who work in the tourism industry, who travel to spend their leisure time, or those who travel to earn knowledge and experience cultural exchange would suffer from negative feelings such as loneliness, discrimination, anxiety, depression, and even PTSD symptoms. Impact on the education system of COVID19 pandemic was mainly reflected through school closure, and associated with quarantine, internet addiction behavior, parents' working hour contraction, and students' dropout. The major mental consequences of these changes in economic activities induced by the pandemic were seclusion, panic attacks, comorbid sleep problems, and depression in more serious cases. Healthcare system is another severely vibrated social system by COVID-19. Imbalanced medical resource allocation and declined 
TABLE 2 | Summary of findings comparing prevalence of mental health problems between the employed and the unemployed.

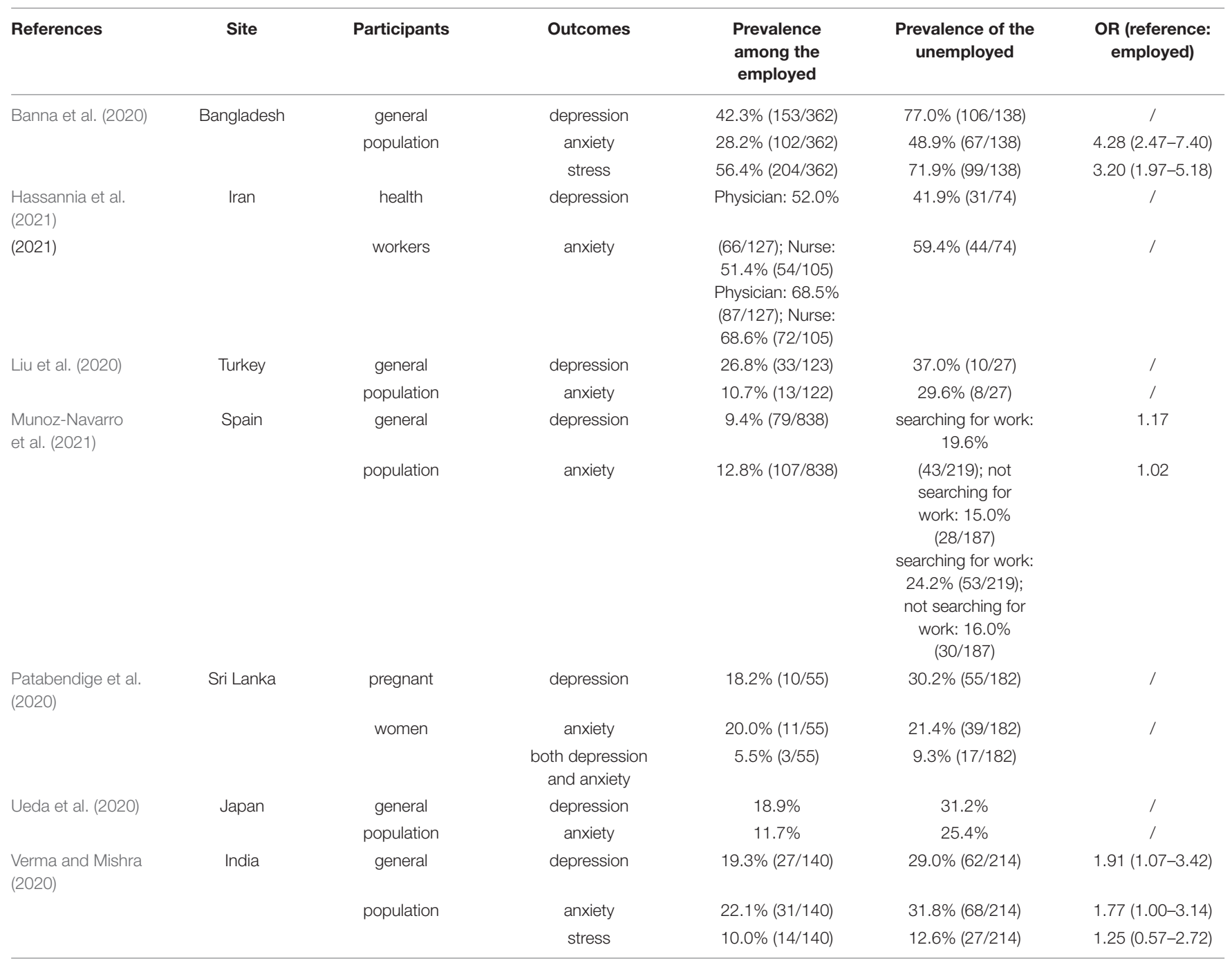

healthcare utilization is related to negative consequences of relevant economic activities as well as mental health problems of healthcare personnel and patients. Adverse mental experiences of HCWS, especially frontline HCWs, have been extensively studied. Precarious employment was a problem suffered by millions of people following the outbreak of COVID-19. Unemployed and underemployed individuals suffer from not only physical, but also mental hardship.

With the realization of the huge economic turmoil brought by COVID-19 pandemic and so many sectors affected, governments across the globe should take actions to mitigate the economic loss and mental health burden. First, the government should consider its own situation and come up with economic recovery policies targeting at the sectors mostly affected by the pandemic. For example, as face-to-face interaction between healthcare professionals and patients or between teachers and students have been limited, productivity by embracing digital manufacturing technologies can be increased in a more cost-effective marketing strategy in order to keep the balance of healthcare and education systems (Lodha and De Sousa, 2020; Kim and Lee, 2021).
Aforementioned MRPs should also be cautiously applied by different governments. Although studies in China showed that isolation-and-quarantine was the most cost-effective intervention in controlling COVID-19, results of studies in other countries can be inconsistent (Rezapour et al., 2021). Therefore, when publicizing strategies to limit virus transmission, the national economic burden as well as individuals' psychological responses should be considered. Second, we suggest governments or policy makers in different countries to share information and experience in dealing with COVID-19-induced economic slowdown and promote herd immunity worldwide to the status quo of the normalization of epidemic prevention. The vaccine can be a strong candidate in controlling the COVID-19 outbreak as well as saving economic loss due to the outbreak as it can help the public to acquire herd immunity in a shorter period which is an effective weapon in fighting against the virus (Sarkodie and Owusu, 2020; Zheng et al., 2021b). Waiting for herd immunity achievement through natural infecting is expected to lose 0.42 years of life per capita compared to the pre-pandemic situation (Gandjour, 2020). A study in the 
TABLE 3 | Summary of findings exploring the association between income and mental health problems.

\begin{tabular}{|c|c|c|c|c|c|c|}
\hline References & Site & Participants & Outcomes & $\begin{array}{l}\text { Prevalence in low } \\
\text { income group }\end{array}$ & $\begin{array}{l}\text { Prevalence in } \\
\text { high income } \\
\text { group }\end{array}$ & $\begin{array}{l}\text { OR (reference: } \\
\text { low income) }\end{array}$ \\
\hline & & & anxiety & $29.5 \%(106 / 360)$ & $36.9 \%(164 / 445)$ & $1.49(1.11-2.22)$ \\
\hline & & & stress & $53.2 \%(191 / 360)$ & $63.8 \%(284 / 445)$ & $1.67(1.18-2.33)$ \\
\hline \multirow[t]{2}{*}{$\begin{array}{l}\text { Munoz-Navarro } \\
\text { et al. (2021) }\end{array}$} & Spain & general population & depression & $17.2 \%(43 / 250)$ & $3.2 \%(4 / 125)$ & / \\
\hline & & & anxiety & $20.4 \%(51 / 250)$ & $12.8 \%(16 / 125)$ & / \\
\hline \multirow[t]{4}{*}{ Naser et al. (2020) } & Jordan & general population & severe depression & / & / & $0.50(0.30-0.82)$ \\
\hline & & & severe anxiety & / & / & $0.70(0.39-1.26)$ \\
\hline & & health worker & severe depression & / & / & $0.38(0.20-0.71)$ \\
\hline & & & severe anxiety & / & / & $0.42(0.18-0.98)$ \\
\hline & & & anxiety & / & / & $1.01(0.60-1.71)$ \\
\hline & & & insomnia & / & / & $0.60(0.28-1.27)$ \\
\hline \multirow[t]{4}{*}{ Shi et al. (2020) } & China & general population & depression & / & / & $0.74(0.69-0.78)$ \\
\hline & & & anxiety & / & / & $0.75(0.71-0.79)$ \\
\hline & & & insomnia & / & / & $0.91(0.86-0.96)$ \\
\hline & & & stress & / & / & $0.79(0.77-0.84)$ \\
\hline \multirow{3}{*}{$\begin{array}{l}\text { Verma and Mishra } \\
\text { (2020) }\end{array}$} & India & general population & depression & $25.9 \%(15 / 58)$ & $25.0 \%(74 / 296)$ & $0.91(0.46-1.75)$ \\
\hline & & & anxiety & $27.6 \%(16 / 58)$ & $28.0 \%(83 / 296)$ & $0.83(0.42-1.61)$ \\
\hline & & & stress & $8.6 \%(5 / 58)$ & $12.2 \%(36 / 296)$ & $0.72(0.26-2.04)$ \\
\hline Zheng et al. (2021a) & China & $\begin{array}{l}\text { older adults (age } \\
\qquad>50)\end{array}$ & depression & $22.6 \%(201 / 888)$ & $16.7 \%(184 / 1100)$ & $0.74(0.57-0.96)$ \\
\hline
\end{tabular}

United States suggested that social distancing would not be a cost-effective strategy unless an effective therapy or vaccine could be introduced within 11.1 months of late May 2020 (Thunstrom et al., 2020). Increasing studies have been established and informed the vaccination prioritization (Kohli et al., 2021; Padula et al., 2021; Wang W. C. et al., 2021). Third, stigmatization resulted from misinformation and invalid communication can hinder the application of cost-effective strategies in flattening the COVID-19 curve. Moreover, stigmatization toward mental problems plays a significant and negative role in increasing the psychological burden of individuals with mental health problems, especially in some low-income countries with inadequate mental health services (Kuruthukulangara and Goyal, 2020). In order to minimize the adverse consequence of COVID-19 pandemic and economic shock on the public mental health status, mental health sectors around the world are encouraged to communicate, cooperate and work together when necessary to protect the mental wellbeing of people around the world. We encourage more valid and effective international communications and cooperation in controlling the virus transmission, economic loss, and increased mental health problems induced by the pandemic.
Even though we made efforts to review existing literatures as thoroughly as possible to reveal the economic consequences of COVID-19 and successive mental problems, there are still some limitations in the current article. It is difficult for us to conclude a causal or directional relationship between COVID-19, economic slowdown, and mental health problems. We can only propose a progressive relationship between the three based on current literatures with limited data sources. Besides, we can only display the interrelationship between the three macroscopically. We were unable to look more deeply into the condition of each nation due to the lack of data support in many developing or low-income countries.

Broadly speaking, COVID-19 had induced economic slowdown and adverse mental consequences worldwide with a proposed progressive relationship in between. International trade, worldwide travel, education system, healthcare system, and individual employment condition are major economic aspects that have been affected by COVID-19 pandemic. Loneliness, insecurity, anxiety, depression, sleep problems, discrimination, and substance abuse are adverse mental consequences experienced by individuals experiencing economic 
turmoil during the pandemic. We call on countries to strengthen cooperation and communication and actively adopt a broad range of economic recovery programs including the adoption of digital and remote trade, education and medical programs and COVID-19 vaccine popularization plan to promote economic recovery to further improve the wellbeing of mental health among multiple vulnerable population worldwide.

\section{AUTHOR CONTRIBUTIONS}

LL, YB, and SM designed the idea of review and revised the manuscript. YG and XL wrote the draft manuscript. XL, YZ, and

\section{REFERENCES}

Alshekaili, M., Hassan, W., Al Said, N., Al Sulaimani, F., Jayapal, S. K., AlMawali, A., et al. (2020). Factors associated with mental health outcomes across healthcare settings in Oman during COVID-19: frontline versus non-frontline healthcare workers. BMJ Open 10:e042030. doi: 10.1136/bmjopen-2020-042030

Alvi, M., and Gupta, M. (2020). Learning in times of lockdown: how Covid-19 is affecting education and food security in India. Food Secur. 12, 793-796. doi: 10.1007/s12571-020-01065-4

An, L., Wynne, M. A., and Zhang, R. (2021). Shock-dependent exchange rate passthrough: evidence based on a narrative sign approach for Japan. J. Int. Money Finance 118:102462. doi: 10.24149/gwp379

Arredondo, E., Kashyap, R., and Surani, S. (2021). Tsunami of economic turmoil to hit the healthcare in 2021-2022: COVID-19 pandemic is just an earthquake. Hosp. Pract. 1995, 1-8. doi: 10.1080/21548331.2021.1917896

Ataguba, J. E. (2020). COVID-19 pandemic, a war to be won: understanding its economic implications for Africa. Appl. Health Econ. Health Policy 18, 325-328. doi: 10.1007/s40258-020-00580-x

Badellino, H., Gobbo, M. E., Torres, E., Aschieri, M. E., Biotti, M., Alvarez, V., et al. (2021). 'It's the economy, stupid': lessons of a longitudinal study of depression in Argentina. Int. J. Soc. Psychiatry [Epub ahead of print]. doi: $10.1177 / 0020764021999687$

Balke, N. S., Fulmer, M., and Zhang, R. (2017). Incorporating the beige book into a quantitative index of economic activity. J. Forecast. 36, 497-514. doi: $10.1002 /$ for. 2450

Balke, N. S., Zeng, Z., and Zhang, R. (2021). Identifying credit demand, financial intermediation, and supply of funds shocks: a structural VAR approach. N. Am. J. Econ. Financ. 56:101375. doi: 10.1016/j.najef.2021.101375

Bambra, C. (2011). Work, worklessness and the political economy of health inequalities. J. Epidemiol. Community Health 65, 746-750. doi: 10.1136/jech. 2009.102103

Banna, M. H. A., Sayeed, A., Kundu, S., Christopher, E., Hasan, M. T., Begum, M. R., et al. (2020). The impact of the COVID-19 pandemic on the mental health of the adult population in Bangladesh: a nationwide cross-sectional study. Int. J. Environ. Health Res. [Epuba ahead of print]. doi: 10.1080/ 09603123.2020.1802409

Bao, Y., Sun, Y., Meng, S., Shi, J., and Lu, L. (2020). 2019-nCoV epidemic: address mental health care to empower society. Lancet 395, e37-e38. doi: 10.1016/ s0140-6736(20)30309-3

Barlow, P., van Schalkwyk, M. C., McKee, M., Labonte, R., and Stuckler, D. (2021). COVID-19 and the collapse of global trade: building an effective public health response. Lancet Planet Health 5, e102-e107. doi: 10.1016/s2542-5196(20) 30291-6

Barrea, L., Pugliese, G., Framondi, L., Di Matteo, R., Laudisio, D., Savastano, S., et al. (2020). Does Sars-Cov-2 threaten our dreams? Effect of quarantine on sleep quality and body mass index. J. Transl. Med. 18:318. doi: 10.1186/s12967020-02465-y

Bocchino, A., Gilart, E., Roman, I. C., and Lepiani, I. (2021). Unemployment syndrome during COVID-19: a comparison of three population groups. Int. J. Environ. Res. Public Health 18:7372. doi: 10.3390/ijerph18147372
HM constructed figures. JQ, KY, WY, and LS reviewed and edited the manuscript. All authors contributed equally to the idea of the manuscript and approved the final manuscript.

\section{FUNDING}

This study was supported by grants from the Ministry of Science and Technology of the People's Republic of China (Nos. 2021YFC0863700, 2019YFA0706200, and 2021ZD0201900), the National Natural Science Foundation of China (Nos. 81761128036, 82171514, and 81901352), and the PKU-Baidu Fund (No. 2020BD011).

Brenner, M. H., and Bhugra, D. (2020). Acceleration of anxiety, depression, and suicide: secondary effects of economic disruption related to COVID-19. Front. Psychiatry 11:592467. doi: 10.3389/fpsyt.2020.592467

Capello, R., and Caragliu, A. (2021). Regional growth and disparities in a postCOVID Europe: a new normality scenario. J. Reg. Sci. [Epub ahead of print]. doi: 10.1111 /jors.12542

Capuano, R., Altieri, M., Bisecco, A., d’Ambrosio, A., Docimo, R., Buonanno, D., et al. (2021). Psychological consequences of COVID-19 pandemic in Italian MS patients: signs of resilience? J. Neurol. 268, 743-750. doi: 10.1007/s00415-02010099-9

Colantone, I., Crinò, R., and Ogliari, L. (2019). Globalization and mental distress. J. Int. Econ. 119, 181-207. doi: 10.1016/j.jinteco.2019.04.008

Creese, B., Khan, Z., Henley, W., O’Dwyer, S., Corbett, A., Vasconcelos Da Silva, M., et al. (2021). Loneliness, physical activity, and mental health during COVID19: a longitudinal analysis of depression and anxiety in adults over the age of 50 between 2015 and 2020. Int. Psychogeriatr. 33, 505-514. doi: 10.1017/ s1041610220004135

Cross, M., Ng, S. K., and Scuffham, P. (2020). Trading health for wealth: the effect of COVID-19 response stringency. Int. J. Environ. Res. Public Health 17:8725. doi: 10.3390/ijerph17238725

d'Ettorre, G., Ceccarelli, G., Santinelli, L., Vassalini, P., Innocenti, G. P., Alessandri, F., et al. (2021). Post-traumatic stress symptoms in healthcare workers dealing with the covid-19 pandemic: a systematic review. Int. J. Environ. Res. Public Health 18:601. doi: 10.3390/ijerph18020601

Di Filippo, P., Attanasi, M., Dodi, G., Porreca, A., Raso, M., Di Pillo, S., et al. (2021). Evaluation of sleep quality and anxiety in Italian pediatric healthcare workers during the first wave of COVID-19 pandemic. BMC Res. Notes 14:219. doi: 10.1186/s13104-021-05621-9

Economou, M., Madianos, M., Peppou, L. E., Patelakis, A., and Stefanis, C. N. (2013). Major depression in the era of economic crisis: a replication of a crosssectional study across Greece. J. Affect. Disord. 145, 308-314. doi: 10.1016/j.jad. 2012.08.008

Edoka, I., Fraser, H., Jamieson, L., Meyer-Rath, G., and Mdewa, W. (2021). Inpatient care costs of covid-19 in South Africa's public healthcare system. Int. J. Health Policy Manag. [Epub ahead of print]. doi: 10.34172/ijhpm.2021.24

Fezzi, C., and Fanghella, V. (2020). Real-time estimation of the short-run impact of COVID-19 on economic activity using electricity market data. Environ. Resour. Econ. 76, 885-900. doi: 10.1007/s10640-020-00467-4

Gallagher, S., and Wetherell, M. A. (2020). Risk of depression in family caregivers: unintended consequence of COVID-19. BJPsych. Open 6:e119. doi: 10.1192/bjo. 2020.99

Gandjour, A. (2020). The clinical and economic value of a successful shutdown during the SARS- CoV-2 pandemic in Germany. Q. Rev. Econ. Finance [Epub ahead of print]. doi: 10.1016/j.qref.2020.10.007

Ge, J., Polhill, J. G., Macdiarmid, J. I., Fitton, N., Smith, P., Clark, H., et al. (2021). Food and nutrition security under global trade: a relation-driven agent-based global trade model. R. Soc. Open Sci. 8:201587. doi: 10.1098/rsos.201587

Gili, M., Roca, M., Basu, S., McKee, M., and Stuckler, D. (2013). The mental health risks of economic crisis in Spain: evidence from primary care centres, 2006 and 2010. Eur. J. Public Health 23, 103-108. doi: 10.1093/eurpub/cks035 
Giorgi, G., Lecca, L. I., Alessio, F., Finstad, G. L., Bondanini, G., Lulli, L. G., et al. (2020). COVID-19-related mental health effects in the workplace: a narrative review. Int. J. Environ. Res. Public Health 17:7857. doi: 10.3390/ijerph17217857

Gopalan, H. S., and Misra, A. (2020). COVID-19 pandemic and challenges for socio-economic issues, healthcare and National Health Programs in India. Diabetes Metab. Syndr. 14, 757-759. doi: 10.1016/j.dsx.2020.05.041

Guan, D., Wang, D., Hallegatte, S., Davis, S. J., Huo, J., Li, S., et al. (2020). Global supply-chain effects of COVID-19 control measures. Nat. Hum. Behav. 4, 577-587. doi: 10.1038/s41562-020-0896-8

Hasan, N., and Bao, Y. (2020). Impact of "e-Learning crack-up" perception on psychological distress among college students during COVID-19 pandemic: a mediating role of "fear of academic year loss". Child. Youth Serv. Rev. 118:105355. doi: 10.1016/j.childyouth.2020.105355

Hassannia, L., Taghizadeh, F., Moosazadeh, M., Zarghami, M., Taghizadeh, H., Dooki, A. F., et al. (2021). Anxiety and depression in health workers and general population during COVID-19 in IRAN: a cross-sectional study. Neuropsychopharmacol. Rep. 41, 40-49. doi: 10.1002/npr2.12153

Huang, A., Makridis, C., Baker, M., Medeiros, M., and Guo, Z. (2020). Understanding the impact of COVID-19 intervention policies on the hospitality labor market. Int. J. Hosp. Manag. 91:102660. doi: 10.1016/j.ijhm.2020.1 02660

Imo, U. O. (2017). Burnout and psychiatric morbidity among doctors in the UK: a systematic literature review of prevalence and associated factors. BJPsych. Bull. 41, 197-204. doi: 10.1192/pb.bp.116.054247

International Monetary Fund (2021). IFS. Available online at: https://data.imf.org/ regular.aspx?key=61545854 (accessed September 15, 2021).

Jalal, S. M., Beth, M. R. M., Al-Hassan, H. J. M., and Alshealah, N. M. J. (2021). Body mass index, practice of physical activity and lifestyle of students during COVID-19 lockdown. J. Multidiscip. Healthc. 14, 1901-1910. doi: 10.2147/ jmdh.S325269

Jin, H., Wang, H., Li, X., Zheng, W., Ye, S., Zhang, S., et al. (2021). Economic burden of COVID-19, China, January-March, 2020: a cost-of-illness study. Bull. World Health Organ. 99, 112-124. doi: 10.2471/blt.20.267112

Johnson, M. S., Skjerdingstad, N., Ebrahimi, O. V., Hoffart, A., and Urnes Johnson, S. (2021). Mechanisms of parental distress during and after the first COVID19 lockdown phase: a two-wave longitudinal study. PLoS One 16:e253087. doi: 10.1371/journal.pone.0253087

Kaur, M., Goyal, P., and Goyal, M. (2020). Individual, interpersonal and economic challenges of underemployment in the wake of COVID-19. Work 67, 21-28. doi: 10.3233 /wor-203249

Keogh-Brown, M. R., Jensen, H. T., Edmunds, W. J., and Smith, R. D. (2020). The impact of Covid-19, associated behaviours and policies on the UK economy: a computable general equilibrium model. SSM Popul. Health 12:100651. doi: 10.1016/j.ssmph.2020.100651

Kim, H. K., and Lee, C. W. (2021). Relationships among healthcare digitalization, social capital, and supply chain performance in the healthcare manufacturing industry. Int. J. Environ. Res. Public Health 18:1417. doi: 10.3390/ijerph18041417

Kohli, M., Maschio, M., Becker, D., and Weinstein, M. C. (2021). The potential public health and economic value of a hypothetical COVID-19 vaccine in the United States: use of costeffectiveness modeling to inform vaccination prioritization. Vaccine 39, 1157-1164. doi: 10.1016/j.vaccine.2020.12.078

Ksinan Jiskrova, G., Bobak, M., Pikhart, H., and Ksinan, A. J. (2021). Job loss and lower healthcare utilisation due to COVID-19 among older adults across 27 European countries. J. Epidemiol. Commun. Health 75, 1078-1083. doi: 10.1136/jech-2021-216715

Kuruthukulangara, S., and Goyal, S. (2020). COVID-19 pandemic and mental health: from risk to resilience. J. Mar. Res. 22, 105-109. doi: 10.4103/jmms. jmms_188_20

Lai, A. Y., Lee, L., Wang, M. P., Feng, Y., Lai, T. T., Ho, L. M., et al. (2020). Mental health impacts of the COVID-19 pandemic on international university students, related stressors, and coping strategies. Front. Psychiatry 11:584240. doi: $10.3389 /$ fpsyt. 2020.584240

Lempel, H., Epstein, J. M., and Hammond, R. A. (2009). Economic cost and health care workforce effects of school closures in the U.S. PLoS Curr. 1:Rrn1051. doi: 10.1371/currents.rrn1051

Leong Bin Abdullah, M. F. I., Mansor, N. S., Mohamad, M. A., and Teoh, S. H. (2021). Quality of life and associated factors among university students during the COVID-19 pandemic: a cross-sectional study. BMJ Open 11:e048446. doi: 10.1136/bmjopen-2020-048446

Levy, I., and Cohen-Louck, K. (2021). Predicting individual function during COVID-19 lockdown: depression, fear of COVID-19, age, and employment. Front. Psychol. 12:682122. doi: 10.3389/fpsyg.2021.682122

Li, H., Hafeez, H., and Zaheer, M. A. (2020). COVID-19 and pretentious psychological well-being of students: a threat to educational sustainability. Front. Psychol. 11:628003. doi: 10.3389/fpsyg.2020.628003

Li, J., Liang, W., Yuan, B., and Zeng, G. (2020). Internalized stigmatization, social support, and individual mental health problems in the public health crisis. Int. J. Environ. Res. Public Health 17:4507. doi: 10.3390/ijerph17124507

Li, X. Y., Wang, J., Zhang, R. X., Chen, L., He, C. K., Wang, C. Y., et al. (2020). Psychological status among anesthesiologists and operating room nurses during the outbreak period of COVID-19 in Wuhan, China. Front. Psychiatry 11:574143. doi: 10.3389/fpsyt.2020.574143

Liang, Y., Wu, K., Zhou, Y., Huang, X., Zhou, Y., and Liu, Z. (2020). Mental health in frontline medical workers during the 2019 novel coronavirus disease epidemic in China: a comparison with the general population. Int. J. Environ. Res. Public Health 17:6550. doi: 10.3390/ijerph17186550

Lin, Y. C., Chang, Y. H., and Yan, H. T. (2020). Is trade a blessing or a curse? A panel data analysis of the determinants of depressive disorders. Int. J. Public Health 65, 1113-1121. doi: 10.1007/s00038-020-01410-6

Liu, X., Luo, W. T., Li, Y., Li, C. N., Hong, Z. S., Chen, H. L., et al. (2020). Psychological status and behavior changes of the public during the COVID-19 epidemic in China. Infect. Dis. Poverty 9:58. doi: 10.1186/s40249-020-00678-3

Lodha, P., and De Sousa, A. (2020). Mental health perspectives of COVID-19 and the emerging role of digital mental health and telepsychiatry. Arch. Med. Health Sci. 8, 133-139. doi: 10.4103/amhs.amhs_82_20

Martinez-de-Quel, O., Suarez-Iglesias, D., Lopez-Flores, M., and Perez, C. A. (2021). Physical activity, dietary habits and sleep quality before and during COVID-19 lockdown: a longitudinal study. Appetite 158:105019. doi: 10.1016/ j.appet.2020.105019

Matilla-Santander, N., Ahonen, E., Albin, M., Baron, S., Bolibar, M., Bosmans, K., et al. (2021). COVID-19 and precarious employment: consequences of the evolving crisis. Int. J. Health Serv. 51, 226-228. doi: 10.1177/0020731420986694

McGinty, E. E., Presskreischer, R., Han, H., and Barry, C. L. (2020). Psychological distress and loneliness reported by US adults in 2018 and April 2020. JAMA 324, 93-94. doi: 10.1001/jama.2020.9740

McInerney, M., Mellor, J. M., and Nicholas, L. H. (2013). Recession depression: mental health effects of the 2008 stock market crash. J. Health Econ. 32, 1090-1104. doi: 10.1016/j.jhealeco.2013.09.002

Megalakaki, O., Kokou-Kpolou, C. K., Vaude, J., Park, S., Iorfa, S. K., Cenat, J. M., et al. (2021). Does peritraumatic distress predict PTSD, depression and anxiety symptoms during and after COVID-19 lockdown in France? A prospective longitudinal study. J. Psychiatr. Res. 137, 81-88. doi: 10.1016/j.jpsychires.2021. 02.035

Mei, H., Li, N., Li, J., Zhang, D., Cao, Z., Zhou, Y., et al. (2021). Depression, anxiety, and stress symptoms in pregnant women before and during the COVID-19 pandemic. J. Psychosom. Res. 149:110586. doi: 10.1016/j.jpsychores.2021.110586

Meng, S. Q., Dong, P., Sun, Y., Li, Y., Chang, X., Sun, G. Q., et al. (2020). Guidelines for prevention and treatment of internet addiction in adolescents during home quarantine for the COVID-19 pandemic. Heart Mind 4, 95-99. doi: $10.4103 / \mathrm{hm} . \mathrm{hm} \_36 \_20$

Munoz-Navarro, R., Cano Vindel, A., Schmitz, F., Cabello, R., and FernandezBerrocal, P. (2021). Emotional disorders during the COVID-19 outbreak in Spain: the role of sociodemographic risk factors and cognitive emotion regulation strategies. Health Educ. Behav. 48, 412-423. doi: 10.1177/ 10901981211014101

Muthuprasad, T., Aiswarya, S., Aditya, K. S., and Jha, G. K. (2021). Students' perception and preference for online education in India during COVID-19 pandemic. Soc. Sci. Humanit. Open 3:100101. doi: 10.1016/j.ssaho.2020.100101

Naser, A. Y., Dahmash, E. Z., Al-Rousan, R., Alwafi, H., Alrawashdeh, H. M., Ghoul, I., et al. (2020). Mental health status of the general population, healthcare professionals, and university students during 2019 coronavirus disease outbreak in Jordan: a cross-sectional study. Brain Behav. 10:e01730. doi: $10.1002 /$ brb3.1730

National Accounts of Japan (2021). Cabinet Office. Available online at: https://www. esri.cao.go.jp/en/sna/menu.html (accessed September 15, 2021). 
Nicola, M., Alsafi, Z., Sohrabi, C., Kerwan, A., Al-Jabir, A., Iosifidis, C., et al. (2020). The socioeconomic implications of the coronavirus pandemic (COVID-19): a review. Int. J. Surg. 78, 185-193. doi: 10.1016/j.ijsu.2020.04.018

Okereke, M., Ukor, N. A., Adebisi, Y. A., Ogunkola, I. O., Favour Iyagbaye, E., Adiela Owhor, G., et al. (2021). Impact of COVID-19 on access to healthcare in low- and middle-income countries: current evidence and future recommendations. Int. J. Health Plann. Manage 36, 13-17. doi: 10.1002/hpm. 3067

Pacheco, J. A. (2020). The "new normal" in education. Prospects 51, 3-14. doi: 10.1007/s11125-020-09521-x

Padula, W. V., Malaviya, S., Reid, N. M., Cohen, B. G., Chingcuanco, F., Ballreich, J., et al. (2021). Economic value of vaccines to address the COVID-19 pandemic: a U.S. cost-effectiveness and budget impact analysis. J. Med. Econ. 24, 1060-1069. doi: 10.1080/13696998.2021.1965732

Patabendige, M., Gamage, M. M., Weerasinghe, M., and Jayawardane, A. (2020). Psychological impact of the COVID-19 pandemic among pregnant women in Sri Lanka. Int. J. Gynaecol. Obstet. 151, 150-153. doi: 10.1002/ijgo.13335

Peng, R., Zhou, W., Zhou, D., Chu, M., and Ling, L. (2021). The mediating role of fatigue between mental health and its associated factors: evidence from chinese healthcare workers during the COVID-19 pandemic. Front. Psychiatry 12:665992. doi: 10.3389/fpsyt.2021.665992

Pieh, C., Budimir, S., Humer, E., and Probst, T. (2021). Comparing mental health during the COVID-19 lockdown and 6 months after the lockdown in Austria: a longitudinal study. Front. Psychiatry 12:625973. doi: 10.3389/fpsyt.2021.6 25973

Pinilla, J., Barber, P., Vallejo-Torres, L., Rodiiguez-Mireles, S., Lopez-Valcarcel, B. G., and Serra- Majem, L. (2021). The economic impact of the SARS-COV2 (COVID-19) pandemic in Spain. Int. J. Environ. Res. Public Health 18:4708. doi: $10.3390 /$ ijerph 18094708

Pollock, A., Campbell, P., Cheyne, J., Cowie, J., Davis, B., McCallum, J., et al. (2020). Interventions to support the resilience and mental health of frontline health and social care professionals during and after a disease outbreak, epidemic or pandemic: a mixed methods systematic review. Cochrane Database Syst. Rev. 11:CD013779. doi: 10.1002/14651858.CD013779

Que, J., Shi, L., Deng, J., Liu, J., Zhang, L., Wu, S., et al. (2020). Psychological impact of the COVID-19 pandemic on healthcare workers: a cross-sectional study in China. Gen. Psychiatr. 33:e100259. doi: 10.1136/gpsych-2020100259

Quigley, A. L., Stone, H., Nguyen, P. Y., Chughtai, A. A., and MacIntyre, C. R. (2021). Estimating the burden of COVID-19 on the Australian healthcare workers and health system during the first six months of the pandemic. Int. J. Nurs. Stud. 114:103811. doi: 10.1016/j.ijnurstu.2020.103811

Ramiz, L., Contrand, B., Rojas Castro, M. Y., Dupuy, M., Lu, L., Sztal-Kutas, C., et al. (2021). A longitudinal study of mental health before and during COVID19 lockdown in the French population. Glob. Health 17:29. doi: 10.1186/s12992021-00682-8

Rasul, G., Nepal, A. K., Hussain, A., Maharjan, A., Joshi, S., Lama, A., et al. (2021). Socioeconomic implications of COVID-19 pandemic in South Asia: emerging risks and growing challenges. Front. Sociol. 6:629693. doi: 10.3389/fsoc.2021. 629693

Reeves, A., Clair, A., McKee, M., and Stuckler, D. (2016). Reductions in the United Kingdom's government housing benefit and symptoms of depression in low-income households. Am. J. Epidemiol. 184, 421-429. doi: 10.1093/aje/ kww055

Repon, M. A. U., Pakhe, S. A., Quaiyum, S., Das, R., Daria, S., and Islam, M. R. (2021). Effect of COVID-19 pandemic on mental health among Bangladeshi healthcare professionals: a cross-sectional study. Sci. Prog. 104:368504211026409. doi: 10.1177/00368504211026409

Rezapour, A., Souresrafil, A., Peighambari, M. M., Heidarali, M., and TashakoriMiyanroudi, M. (2021). Economic evaluation of programs against COVID19: a systematic review. Int. J. Surg. 85, 10-18. doi: 10.1016/j.ijsu.2020. 11.015

Rosen, M., and Stenbeck, M. (2021). Interventions to suppress the coronavirus pandemic will increase unemployment and lead to many premature deaths. Scand. J. Public Health 49, 64-68. doi: 10.1177/1403494820947974

Sadique, M. Z., Adams, E. J., and Edmunds, W. J. (2008). Estimating the costs of school closure for mitigating an influenza pandemic. BMC Public Health 8:135. doi: $10.1186 / 1471-2458-8-135$
Salfi, F., Lauriola, M., Amicucci, G., Corigliano, D., Viselli, L., Tempesta, D., et al. (2020). Gender-related time course of sleep disturbances and psychological symptoms during the COVID-19 lockdown: a longitudinal study on the Italian population. Neurobiol. Stress 13:100259. doi: 10.1016/j.ynstr.2020.100259

Sarkodie, S. A., and Owusu, P. A. (2020). Global assessment of environment, health and economic impact of the novel coronavirus (COVID-19). Environ. Dev. Sustain. 23, 5005-5015. doi: 10.1007/s10668-020-00801-2

Shang, Y., Li, H., and Zhang, R. (2021). Effects of pandemic outbreak on economies: evidence from business history context.". Front. Public Health 9:632043. doi: 10.3389/fpubh.2021.632043

Shi, L., Lu, Z. A., Que, J. Y., Huang, X. L., Liu, L., Ran, M. S., et al. (2020). Prevalence of and risk factors associated with mental health symptoms among the general population in China during the coronavirus disease 2019 pandemic. JAMA Netw. Open 3:e2014053. doi: 10.1001/jamanetworkopen.2020.14053

Shi, L., Lu, Z. A., Que, J. Y., Huang, X. L., Lu, Q. D., Liu, L., et al. (2021a). Long-term impact of COVID-19 on mental health among the general public: a nationwide longitudinal study in China. Int. J. Environ. Res. Public Health 18:8790. doi: 10.3390/ijerph18168790

Shi, L., Que, J. Y., Lu, Z. A., Gong, Y. M., Liu, L., Wang, Y. H., et al. (2021b). Prevalence and correlates of suicidal ideation among the general population in China during the COVID-19 pandemic. Eur. Psychiatry 64:e18. doi: 10.1192/j. eurpsy.2021.5

Shih, G., Deer, J. D., Lau, J., Loveland Baptist, L., Lim, D. J., and Lockman, J. L. (2021). The impact of the COVID-19 pandemic on the education and wellness of U.S. Pediatric Anesthesiology Fellows. Paediatr. Anaesth. 31, 268-274. doi: 10.1111/pan.14112

Shreffler, J., Petrey, J., and Huecker, M. (2020). The Impact of COVID-19 on healthcare worker wellness: a scoping review. West. J. Emerg. Med. 21, 10591066. doi: 10.5811/westjem.2020.7.48684

Siddiquei, M. I., and Khan, W. (2020). Economic implications of coronavirus. J. Public Aff. [Epub ahead of print]. doi: 10.1002/pa.2169

Song, B., Zhao, Y., and Zhu, J. (2021). COVID-19-related traumatic effects and psychological reactions among international students. J. Epidemiol. Glob. Health 11, 117-123. doi: 10.2991/jegh.k.201016.001

Strauss, I., Isaacs, G., and Rosenberg, J. (2021). The effect of shocks to GDP on employment in SADC member states during COVID-19 using a Bayesian hierarchical model. Afr. Dev. Rev. 33(Suppl. 1), s221-s237. doi: 10.1111/14678268.12524

Sun, Y. K., Bao, Y. P., Ravindran, A., Sun, Y., Shi, J., and Lu, L. (2020). Mental health challenges raised by rapid socioeconomic transformations in China: lessons learned and prevention strategies. Heart Mind 4, 59-66. doi: 10.4103/hm.hm_ $22 \_20$

The World Bank (2021). Data. Available online at: https://data.worldbank.org/ indicator/NY.GDP.MKTP.CD? end=2020\&locations=JP-DE-FR-IT-ES-CANG-GB-IN-RU-BR-MX-SA-ZA-CN-US\&most_recent_value_desc=false\& start=2020\&view=bar\&year=2019 (accessed September 15, 2021).

Thepphakorn, T., Sooncharoen, S., and Pongcharoen, P. (2021). Particle swarm optimisation variants and its hybridisation ratios for generating cost-effective educational course timetables. SN Comput. Sci. 2:264. doi: 10.1007/s42979-02100652-2

Thill, S., Houssemand, C., and Pignault, A. (2020). Effects of meaning in life and of work on health in unemployment. Health Psychol. Open 7:2055102920967258. doi: $10.1177 / 2055102920967258$

Thunstrom, L., Newbold, S. C., Finnoff, D., Ashworth, M., and Shogren, J. F. (2020). The benefits and costs of using social distancing to flatten the curve for COVID-19. J. Benefit Cost Anal. 11:1934. doi: 10.2139/ssrn.3561934

Tzafilkou, K., Perifanou, M., and Economides, A. A. (2021). Development and validation of a students' remote learning attitude scale (RLAS) in higher education. Educ. Inf. Technol. 26, 7279-7305. doi: 10.1007/s10639-021-1 0586-0

Ueda, M., Stickley, A., Sueki, H., and Matsubayashi, T. (2020). Mental health status of the general population in Japan during the COVID-19 pandemic. Psychiatry Clin. Neurosci. 74, 505-506. doi: 10.1111/pcn.13105

van der Velden, P. G., Contino, C., Das, M., van Loon, P., and Bosmans, M. W. G. (2020). Anxiety and depression symptoms, and lack of emotional support among the general population before and during the COVID-19 pandemic. A prospective national study on prevalence and risk factors. J. Affect Disord. 277, 540-548. doi: 10.1016/j.jad.2020.08.026 
Verma, S., and Mishra, A. (2020). Depression, anxiety, and stress and sociodemographic correlates among general Indian public during COVID-19. Int. J. Soc. Psychiatry 66, 756-762. doi: 10.1177/0020764020934508

Wang, H., Zhou, X., Jia, X., Song, C., Luo, X., Zhang, H., et al. (2021). Emotional exhaustion in front-line healthcare workers during the COVID19 pandemic in Wuhan, China: the effects of time pressure, social sharing and cognitive appraisal. BMC Public Health 21:829. doi: 10.1186/s12889-021-1 0891-w

Wang, W. C., Fann, J. C., Chang, R. E., Jeng, Y. C., Hsu, C. Y., Chen, H. H., et al. (2021). Economic evaluation for mass vaccination against COVID-19. J. Formos. Med. Assoc. 120(Suppl. 1), s95-s105. doi: 10.1016/j.jfma.2021.05.020

Wang, Y. H., Li, J. Q., Shi, J. F., Que, J. Y., Liu, J. J., Lappin, J. M., et al. (2020). Depression and anxiety in relation to cancer incidence and mortality: a systematic review and meta-analysis of cohort studies. Mol. Psychiatry 25, 1487-1499. doi: 10.1038/s41380-019-0595-x

Wilczewski, M., Gorbaniuk, O., and Giuri, P. (2021). The Psychological and academic effects of studying from the home and host country during the COVID-19 pandemic. Front. Psychol. 12:644096. doi: 10.3389/fpsyg.2021. 644096

Woon, L. S., Leong Bin Abdullah, M. F. I., Sidi, H., Mansor, N. S., and Nik Jaafar, N. R. (2021a). Depression, anxiety, and the COVID-19 pandemic: severity of symptoms and associated factors among university students after the end of the movement lockdown. PLoS One 16:e252481. doi: 10.1371/journal.pone. 0252481

Woon, L. S., Mansor, N. S., Mohamad, M. A., Teoh, S. H., and Leong Bin Abdullah, M. F. I. (2021b). Quality of life and its predictive factors among healthcare workers after the end of a movement lockdown: the salient roles of COVID-19 stressors, psychological experience, and social support. Front. Psychol. 12:652326. doi: 10.3389/fpsyg.2021.652326

Xu, Y., Su, S., Jiang, Z., Guo, S., Lu, Q., Liu, L., et al. (2021). Prevalence and risk factors of mental health symptoms and suicidal behavior among university students in Wuhan, China during the COVID-19 pandemic. Front. Psychiatry 12:695017. doi: 10.3389/fpsyt.2021.695017

Yang, F., Lin, W., Frost, E., Min, Y., Xu, X., Wang, X., et al. (2021). Association between contact with a general practitioner and depressive symptoms during the COVID-19 pandemic and lockdown: a large community-based study in Hangzhou, China. BMJ Open 11:e052383. doi: 10.1136/bmjopen-2021-052383

Yao, R., and Wu, W. (2021). Mental disorders associated with COVID-19 related unemployment. Appl. Res. Qual. Life [Epub ahead of print]. doi: 10.1007/ s11482-021-09950-6

Yoshikawa, H., Wuermli, A. J., Britto, P. R., Dreyer, B., Leckman, J. F., Lye, S. J., et al. (2020). Effects of the global coronavirus disease-2019 pandemic on early childhood development: short- and long-term risks and mitigating program and policy Actions. J. Pediatr. 223, 188-193. doi: 10.1016/j.jpeds.2020.05.020

Yuan, K., Gong, Y. M., Liu, L., Sun, Y. K., Tian, S. S., Wang, Y. J., et al. (2021). Prevalence of posttraumatic stress disorder after infectious disease pandemics in the twenty-first century, including COVID-19: a meta-analysis and systematic review. Mol. Psychiatry 26, 4982-4998. doi: 10.1038/s41380021-01036- $\mathrm{x}$

Zhai, Y., and Du, X. (2020). Mental health care for international Chinese students affected by the COVID-19 outbreak. Lancet Psychiatry 7:e22. doi: 10.1016/ s2215-0366(20)30089-4

Zhang, R. (2019). News Shocks and the Effects of Monetary Policy. Available online at: https://ssrn.com/abstract=3348466 (accessed December 8, 2021).

Zhang, Y. N., Chen, Y., Wang, Y., Li, F., Pender, M., Wang, N., et al. (2020). Reduction in healthcare services during the COVID-19 pandemic in China. BMJ Glob. Health 5:e003421. doi: 10.1136/bmjgh-2020-00 3421

Zhao, J., Jin, H., Li, X., Jia, J., Zhang, C., Zhao, H., et al. (2021). Disease burden attributable to the first wave of COVID-19 in China and the effect of timing on the cost-effectiveness of movement restriction policies. Value Health 24, 615-624. doi: 10.1016/j.jval.2020.12.009

Zhao, T., Fu, Z., Lian, X., Ye, L., and Huang, W. (2021). Exploring emotion regulation and perceived control as antecedents of anxiety and its consequences during Covid-19 full remote learning. Front. Psychol. 12:675910. doi: 10.3389/ fpsyg.2021.675910

Zhao, Y. H., Ozdemir, N., Zhang, R., and An, L. (2021). Outward Foreign Direct Investment of China's Banking Sector: Determinants and Motivations. Available online at: https://ssrn.com/abstract=3780899 (accessed December 8, 2021).

Zheng, Y. B., Shi, L., Lu, Z. A., Que, J. Y., Yuan, K., Huang, X. L., et al. (2021a). Mental health status of late-middle-aged adults in China during the coronavirus disease 2019 pandemic. Front. Public Health 9:643988. doi: 10.3389/fpubh.2021. 643988

Zheng, Y. B., Sun, J., Liu, L., Zhao, Y. M., Yan, W., Yuan, K., et al. (2021b). COVID19 vaccine-related psychological stress among general public in China. Front. Psychiatry 12:774504. doi: 10.3389/fpsyt.2021.774504

Conflict of Interest: The authors declare that the research was conducted in the absence of any commercial or financial relationships that could be construed as a potential conflict of interest.

Publisher's Note: All claims expressed in this article are solely those of the authors and do not necessarily represent those of their affiliated organizations, or those of the publisher, the editors and the reviewers. Any product that may be evaluated in this article, or claim that may be made by its manufacturer, is not guaranteed or endorsed by the publisher.

Copyright (c) 2022 Gong, Liu, Zheng, Mei, Que, Yuan, Yan, Shi, Meng, Bao and Lu. This is an open-access article distributed under the terms of the Creative Commons Attribution License (CC BY). The use, distribution or reproduction in other forums is permitted, provided the original author(s) and the copyright owner(s) are credited and that the original publication in this journal is cited, in accordance with accepted academic practice. No use, distribution or reproduction is permitted which does not comply with these terms. 